Sharif University of Technology
Scientia Iranica
Transactions E: Industrial Engineering
wCIENTIA

\title{
Design of an innovative construction model for supply chain management by measuring agility and cost of quality: An empirical study
}

\author{
Y. Rahimi ${ }^{\mathrm{a}}$, R. Tavakkoli-Moghaddam ${ }^{\mathrm{a}, *}$, S. Shojaie ${ }^{\mathrm{b}}$ and I. Cheraghi ${ }^{\mathrm{c}}$ \\ a. School of Industrial Engineering, College of Engineering, University of Tehran, Tehran, Iran. \\ b. School of Industrial Engineering, Iran University of Science and Technology, Tehran, Iran. \\ c. Department of Industrial Engineering, Albourz Campus, University of Tehran, Tehran, Iran.
}

Received 20 July 2015; received in revised form 23 April 2016; accepted 19 September 2016

\section{KEYWORDS}

Construction supply

chain management;

Agility;

Suppliers performance

evaluation;

Cost of quality.

\begin{abstract}
This paper aims to present a model for an agile supply chain network in construction enterprises with performance evaluation of suppliers and contractors. Management and selection of suppliers and contractors play an important role in the process of constructions since contractors are as corner stones of construction projects. Additionally, contractors are the main factor in converting resources to final products. Traditionally, contractor selection in construction projects is on the basis of the lowest proposed price. However, there are various qualitative and quantitative criteria with different priorities associated in this regard in order to make the best decision. In this paper, a hybrid method of DEA/AHP/FDEMATEL is used. First, important and effective evaluation criteria are selected through an FDEMATEL method. Then, the DEA/AHP method is implemented in order to evaluate and prioritize the selected indicators as well as to incorporate them in a supply chain. Furthermore, agility is involved in the considered supply chain network. Furthermore, in this paper, for the first time in Iran, a supply chain model is studied and designed for civil companies.
\end{abstract}

(C) 2017 Sharif University of Technology. All rights reserved.

\section{Introduction}

Efficiency and effectiveness of each organization is obtained through management performance and its supply chain structure. The key to success of today's organizations is laid in perception and recognition of customers' requirements and providing a quick response to them. This results from investigations and

\footnotetext{
*. Corresponding author. Tel.: +982188021067; Fax: +982188013102

E-mail address: tavakoli@ut.ac.ir (R.

Tavakkoli-Moghaddam)
}

doi: $10.24200 /$ sci. 2017.4388 developments in a Supply Chain (SC). Supply Chain Management (SCM) is a set of approaches towards collaboration of suppliers, manufacturers, warehouses, and retailers so that products are delivered to customers in a right amount, time, and location, in which the total cost of the system is minimized through satisfaction of a determined service level [1]. In fact, SCM is managing a set of interrelated issues that are in line with customers' satisfaction [2]. The total aim of SCM is to integrate organizational units and coordinate material flow, information, and money in a way that competency of an SC can be improved [3-5].

Supply chain management in construction projects is defined as follows: management of information flow, actions, activities, and processes including 
various networks of independent organizations and their communication paths (upstream and downstream) that create value in the form of a project for the owner [6]. Upstream activities in an SC of construction projects from the main contractor's point of view include the project owner and engineering/design group that prepare the process of construction. Downstream activities, including material suppliers and secondary contractors that stay in touch with the primary contractors, require high levels of cooperation among beneficiaries of the project. In today's competitive environment, construction organizations have to be connected with the best suppliers and secondary contractors in order to keep their competency advantageous. Often, construction organizations are not expert in determining their suppliers' capabilities and commonly make decisions based on their perceptions. This integrated concern, i.e. process of supplier selection, should melt in supply chain environment in a way that ensures material availability [6]. In Appendix A, two models, i.e. horizontal and vertical, are presented for SCM of construction projects. In this paper, we apply the first pattern for the SC design [6].

Supplier and contractor selection is basically a Multi-Criteria Decision Making (MCDM) problem. However, most organizations deal with this issue from a strategic point of view. The essence of this kind of decisions is highly complex without having a certain structure. Therefore, by applying management tools, e.g. MCDM methods, we can solve them. Regarding the proposed problem and the related literature, a new model is presented in this paper for SCM of construction projects along with supplier and contractor evaluations.

Various models are available in the literature, which are concerned with the supplier selection problem. Wind and Robinson [7] proposed a linear weighting method for rating different vendors in an experimental environment. Also, some studies considered their goals under budget constraints for evaluation of different vendors. For example, goal programming formulation was used for obtaining the goals related to price and quality under different constraints $[8,9]$. There have been several methods used for a supplier selection problem during the past years [10-19]; however, Data Envelopment Analysis (DEA), Analytical Hierarchy Process (AHP), and the Technique for Order Performance by Similarity to Ideal Solution (TOPSIS) are the most popular methods for the vendor (or supplier) selection problem.

Liu et al. [20] presented a DEA method for a vendor selection problem with multiple objectives. Weber et al. [21] combined DEA and mathematical programming models for supplier selection. Kahra- man et al. [22] used a fuzzy AHP to select the best supplier for a manufacturer firm established in Turkey. Guneri et al. [23] introduced an integrated fuzzy-LP approach for a supplier selection problem. Reza [24] proposed an AR-IDEA model for selecting the best suppliers in the presence of both weight restrictions and imprecise data. Sevkli et al. [25] stated that a DEA Hierarchy Process (DEAHP) method had better performance than an AHP method for supplier selection. Kuo et al. [26] used a hybrid of the AHP and DEA for developing performance evaluation to make the supplier selection decision. Zeydan et al. [27] used fuzzy AHP and fuzzy TOPSIS for a supplier selection problem. Zhang et al. [28] used the combined DEAHP model and Activity-Based Costing (ABC) for supplier evaluation. Li et al. [29] combined TOPSIS and 0-1 programming for supplier selection. Lin et al. [30] achieved a novel hybrid MCDM approach for outsourcing vendor selection. Ou Yang et al. [31] introduced a novel hybrid MCDM model combined with DEMATEL and Analytical Network Process (ANP). Xu and Yan [32] discussed the VSP in a bi-fuzzy environment and its application to material supply. Amindoust et al. [33] introduced a new ranking method based on fuzzy inference system for a supplier selection problem to handle subjectivity of decision makers' assessments. Arabzad et al. [34] proposed the model for choosing a supplier based on the Kraljic and DEA models. Lee [35] proposed a fuzzy supplier selection model with the consideration of benefits, opportunities, costs, and risks. Carrera and Mayorga [36] proposed a Fuzzy Inference System (FIS) approach in supplier selection for new product development. Çelebi and Bayraktar [37] proposed a new method for integration of Neural Networks (NN) and DEA for evaluating of suppliers under incomplete information about evaluation criteria. Wu [38] assessed supplier performance by a combination of the DEA, Decision Trees (DT), and NNs models. Sanayei et al. [39] used a VIKOR method under a fuzzy environment to solve multiple-criteria problems of supplier selection. Shi et al. [40] proposed a model based on artificial intelligence (BP neural network) and C2R-DEA for selecting appropriate logistics suppliers.

In this paper, superiorities of the AHP/DEA hybrid method presented by Stern et al. [41] in AHP and DEA methods are studied in case of decision making units' performance evaluation. Also, AHP/DEA is employed for evaluation of decision making units [42]. Many quantitative methods have been presented for performance evaluation and prioritizing of decisionmaking units so far. These methods are Delphi, AHP, ANP, MCDM, DEA, etc. Due to comprehensiveness and efficiency of the AHP/DEA, this method is employed in this study. 


\section{AHP/DEA/FDEMATEL hybrid approach framework}

Supply chains in manufacturing systems are multiechelon networks consisting of suppliers, manufacturers, wholesalers, retailers, and warehouses. In these supply chains, manufacturers or warehouses are fixed, whereas they are not fixed in construction projects. To be more explicit, whenever a project is completed, the workshop, i.e. virtual warehouse, is removed. Hence, warehouses in construction projects can be defined as virtual workshops. The supply chain network proposed in this paper is considered to be agile and virtual once a project, in which this network is applicable, is completed. In this network, a hybrid multi-criteria model is applied. First, this model selects the most favorable influential criteria for supplier and contractor evaluation. Afterwards, it prioritizes them through the hybrid AHP/DEA method. Then, with regard to Figure 1 and inserting the chosen suppliers and contractors in the network, construction supply chain networks are constituted. In this paper, a real case is implemented in the P.G. Company.

P.G. Corporation has remarkable experiences when it comes to dam building, implementation of irrigation and drainage networks, road construction, tunnel drilling, hydraulic heavy concrete and steel construction, marine structures, massive constructions, and design and construction of manufacturing firms. This corporation is licensed grade one under the super-

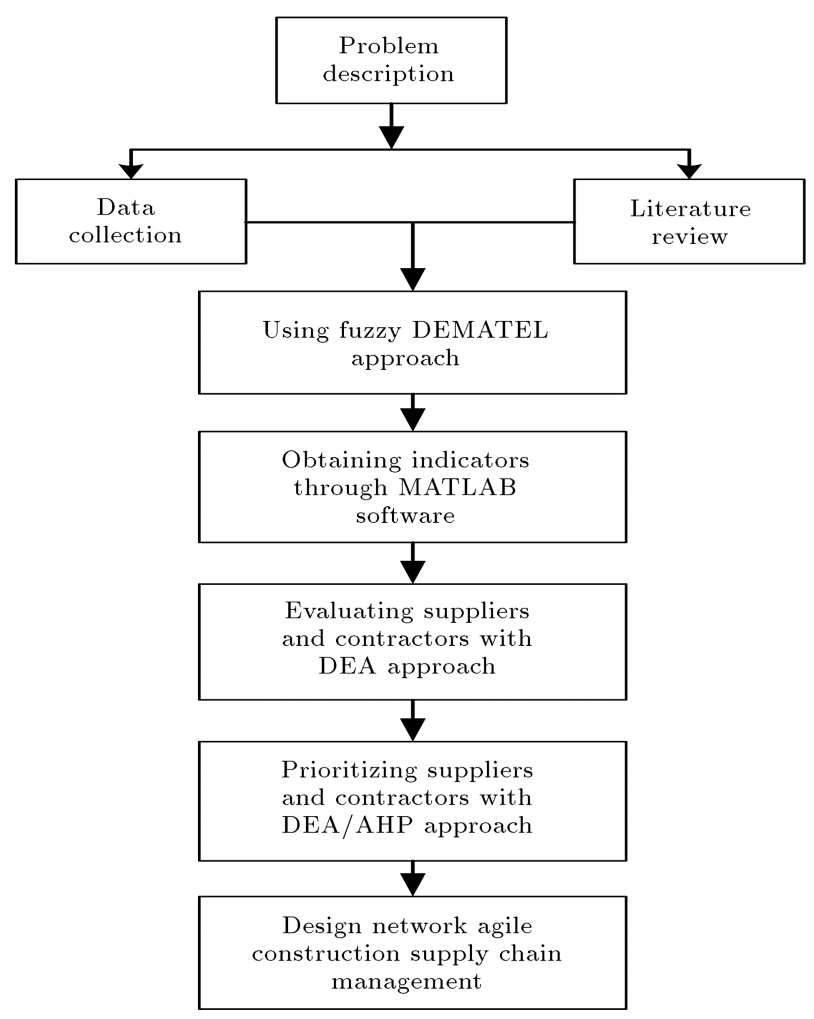

Figure 1. Model framework. vision of president's Strategic Planning and Monitoring Deputy and under the supervision of Iranian Ministry of Housing and Urban Development. The grades of this corporation are as follows:

- Grade one in the fields of water, industry, and mining; roads and transportation; buildings and monuments; facilities and equipment; and massive construction management;

- Grade two in oil and gas industry, and design and construction of buildings and monuments;

- Grade three in the field of power.

P.G. Construction and Industrial Corporation has managed to receive the following licenses since 2003: Integrated Management System (IMS) certified by DQS of Germany, IQNet, Environmental Management System (ISO 14001; 2004), Quality Management System (ISO 9001; 2008), Occupational Health \& Safety Advisory Services (OHSAS 18001; 2007), Risk Management System (ISO 31000; 2009), Customer Satisfaction, and Complaints Handling (DIN ISO 10002; 2005). Furthermore, this corporation is awarded a 5star acknowledgement of EFQM.

\section{Determining performance evaluation criteria by an FDEMATEL method}

In order to evaluate performance of decision-making units, first, it is necessary to determine and study their indicators. In this paper, the FDEMATEL method is employed for supplier/contractor performance evaluation. Finally, regarding specific features of construction companies, important criteria are obtained for both suppliers and contractors.

Fontela and Gabus [43] presented DEMATEL, which was based on paired comparisons. To benefit from experts' judgments in extracting a system's indicators and putting them in a structure through a graph theory, a hierarchical structure with logical relations is acquired [44,45]. The severity of these relations is stated as numerical rates. The DEMATEL method is used for determining and studying mutual relations among criteria and for mapping them onto the network. Since directed graphs can better present the relations among components of a system, the DEMATEL method is on the basis of some diagrams that define the involved components into cause and effects. Also, it draws their relations in an intelligible structural model. It is often used for global complex problems and, similarly, for structuring a sequence of given information. Subsequently, the severity of relations is studied as numerical scores; the feedbacks are searched along with their importance, and the inalienable relations are accepted. The main steps of the DEMATEL method are as: 
- Considering interrelations: This method has an edge over ANP; it has clarity and transparency in mirroring the interrelations among the large sum of components so that experts can express their points of view dominantly towards the effects (direction and effect intensity) among criteria. It is remarkable that, in fact, the occasioned matrix in DEMATEL method (interrelated matrix) constitutes a part of a super-matrix. In other words, DEMATEL acts indirectly and as a subsystem of a larger system such as ANP;

- Structuring complex criteria in the form of cause and effect groups: This issue is one of the most frequently used functions and one of the most important factors in the process of problem solving. In this case, a wide range of complex criteria is divided into smaller subsets in the form of cause and effect groups so that decision maker can perceive the relations more appropriately. This matter leads to better understanding of the position of criteria and their role in mutual effects.

\subsection{Steps of the DEMATEL method}

- Establishing direct relation matrix: The paired comparisons are recognized by experts. Thus, the direct relation matrix $A$, with $n \times n$ dimensions ( $n$ is the number of criteria), is established and $a_{i j}$ is a number which shows effect of criterion $i$ on criterion $j$.

- Normalizing direct relation matrix: The primary normal matrix can be calculated through Eqs. (1) and (2) as follows:

$$
\begin{aligned}
& X=k \times A \\
& k=1 / \max \sum_{j=1}^{n} a_{i j} \quad 1 \leq i \leq n .
\end{aligned}
$$

- Obtaining the general relations matrix: The general relations matrix $(T)$ is represented through Eq. (3). $I$ is an identity matrix:

$$
T=X \times(1-X)^{-1} \text {. }
$$

- Cause and effect diagram establishment: Summation of the rows $(D)$ and summation of the columns $(R)$ in matrix $T$ are obtained by Eqs. (4)(6):

$$
\begin{aligned}
T & =\left[t_{i j}\right]_{n \times n} \quad i, j=1,2, \ldots, n, \\
R & =\left[\sum_{i=1}^{n} t_{i j}\right]_{1 \times n}=\left[t_{j}\right]_{1 \times n} \quad i, j=1,2, \ldots, n, \\
D & =\left[\sum_{i=1}^{n} t_{i j}\right]_{n \times 1}=\left[t_{j}\right]_{n \times 1} \quad i, j=1,2, \ldots, n .
\end{aligned}
$$

Table 1. Linguistic scales for the importance weight of criteria.

\begin{tabular}{cc}
\hline Linguistic terms & Triangular fuzzy numbers \\
\hline No influence & $(0,0.1,0.3)$ \\
Very low influence & $(0.1,0.3,0.5)$ \\
Low influence & $(0.3,0.5,0.7)$ \\
High influence & $(0.5,0.7,0.9)$ \\
Very high influence & $(0.7,0.9,1)$ \\
\hline
\end{tabular}

The horizontal vector of cause and effect diagram $(D+R)$ is called superiority vector, which shows the relative importance of each criterion. The vertical axis $(D-R)$ is named relative vector. If the value of this vector is positive, the corresponding criteria belong to causes and otherwise the corresponding criteria belong to effects.

- Obtaining internal dependency matrix: In this step, summation of the elements of each column in general matrix equals 1 through normalizing method and the internal dependency matrix can be obtained.

Chang et al. [46] and Wu and Lee [47] investigated implementing of a fuzzy DEMATEL. The considered group consisted of 50 experts and specialists (project managers), experienced enough in the field of supplier evaluation in a wide range of projects. They were asked to fill out the questionnaires. The group of experts included 20 experts (project managers), specialists in supplier evaluation. They were asked to express their opinion through filling out the questionnaires. Table 1 shows the linguistic scales for the importance weight of criteria used by specialists.

Regarding the outcome of the DEMATEL method in Tables 2 and 3, the most important and influential indicators are chosen for suppliers and contractors of the corresponding company. The selected indicators are CR 9, CR 20, CR 14, CR 13, and CR 19 for suppliers and CR 20, CR 14, CR 13, CR 19, CR 16, CR 17, and CR 2 for contractors. The names of these indicator are shown in Appendix B. To measure the reliability of the questionnaire, the Cronbach's alpha is used in SPSS 21 software. The product of this method for our questionnaire is 0.85 , which means the questionnaire is reliable enough. Appendix B shows the normalized input and output indicators related to each supplier and contractor. Due to importance of quality as one of the main evaluation criteria for performance of suppliers in civil projects, we decide on the cost of quality recognition and analysis.

\subsection{Analysis of cost of quality indicators in construction projects}

The concept of quality cost in construction projects was introduced in early 1980s, when organizations had 
Table 2. Prominence and relation axes for the cause and effect group for suppliers.

\begin{tabular}{ccccc}
\hline Criteria & $\boldsymbol{R}+\boldsymbol{D}$ & $\boldsymbol{R}-\boldsymbol{D}$ & $\boldsymbol{D}$ & $\boldsymbol{R}$ \\
\hline CR 20 & 50.3325 & -0.66 & 25.49625 & 24.83625 \\
CR 14 & 43.9965 & 11.913 & 16.04175 & 27.95475 \\
CR 13 & 41.1695 & -2.487 & 21.82825 & 19.34125 \\
CR 19 & 40.96125 & -2.00725 & 21.48425 & 19.477 \\
CR 16 & 41.4425 & 1.903 & 19.76975 & 21.67275 \\
CR 17 & 42.36075 & 2.05475 & 20.153 & 22.20775 \\
CR 2 & 42.234 & 5.853 & 18.1905 & 24.0435 \\
CR 10 & 39.0045 & 7.5885 & 15.708 & 23.2965 \\
CR 18 & 37.23375 & -0.23025 & 18.732 & 18.50175 \\
CR 1 & 36.98025 & -3.59925 & 20.28975 & 16.6905 \\
CR 3 & 36.46425 & -0.96075 & 18.7125 & 17.75175 \\
CR 4 & 35.8395 & -5.382 & 20.61075 & 15.22875 \\
CR 12 & 35.697 & -2.3595 & 19.02825 & 16.66875 \\
CR 15 & 33.579 & 7.9635 & 12.80775 & 20.77125 \\
CR 9 & 32.817 & -11.0085 & 21.91275 & 10.90425 \\
CR 8 & 30.74175 & 6.04575 & 12.348 & 18.39375 \\
CR 6 & 27.66375 & 0.86775 & 13.398 & 14.26575 \\
CR 7 & 27.294 & -1.515 & 14.4045 & 12.8895 \\
CR 11 & 22.89 & 0.6555 & 11.11725 & 11.77275 \\
CR 5 & 22.02675 & 3.86025 & 9.08325 & 12.9435 \\
\hline & & & &
\end{tabular}

focused on boosting quality of construction projects. Quality costs are assumed to be total cost of compliances and non-compliances. The cost of compliances or reaching a certain level of quality is that spent to prevent a low level of quality and non-compliances or quality failure; low quality is imposed by defective product or service. A classification model of prevention, inspection, failure is commonly used to define and classify the cost of quality. Regarding the research conducted in construction projects, a noncompliance cost can be reduced from 2 to $10 \%$ through spending more $1 \%$ in a prevention phase. Minimizing the cost of quality to the lowest possible amount is one of the goals of a quality cost system. The basic assumption of P.A.F is that focusing on prevention and inspection will reduce failure cost. In fact, in this paper, we also design a systematic framework for the cost of quality, in which the optimum interval is obtained for the mentioned costs. Quality costs are structured based on the P.A.F model. This approach is achieved by recent studies [48-51] and the experiences of experts as shown in Figure 2. Since the quality cost of suppliers is crucial in construction projects and in the P.G. Company, the suppliers and contractors with the least possible amount of quality costs are selected.
Table 3. Prominence and relation axes for the cause and effect group for contractors.

\begin{tabular}{ccccc}
\hline Criteria & $\boldsymbol{R}+\boldsymbol{D}$ & $\boldsymbol{R}-\boldsymbol{D}$ & $\boldsymbol{D}$ & $\boldsymbol{R}$ \\
\hline CR 9 & 42.35687 & -5.81787 & 24.08737 & 18.2695 \\
CR 20 & 30.1555 & 2.9595 & 13.598 & 16.5575 \\
CR 14 & 33.26155 & 4.01145 & 14.62505 & 18.6365 \\
CR 13 & 28.52445 & -0.06945 & 14.29695 & 14.2275 \\
CR 19 & 28.3096 & -3.6736 & 15.9916 & 12.318 \\
CR 16 & 23.9257 & 4.9713 & 9.4772 & 14.4485 \\
CR 10 & 23.14058 & 7.921416 & 7.609584 & 15.531 \\
CR 17 & 23.0201 & -2.7431 & 12.8816 & 10.1385 \\
CR 12 & 22.52945 & -0.30445 & 11.41695 & 11.1125 \\
CR 18 & 22.3249 & 2.3441 & 9.9904 & 12.3345 \\
CR 2 & 22.1052 & 9.9528 & 6.0762 & 16.029 \\
CR 15 & 21.53215 & 6.16285 & 7.68465 & 13.8475 \\
CR 3 & 19.3195 & 4.3495 & 7.485 & 11.8345 \\
CR 1 & 19.2429 & 3.0111 & 8.1159 & 11.127 \\
CR 4 & 18.3968 & 1.9082 & 8.2443 & 10.1525 \\
CR 8 & 17.2017 & 7.3233 & 4.9392 & 12.2625 \\
CR 6 & 14.8697 & 4.1513 & 5.3592 & 9.5105 \\
CR 11 & 14.51885 & 1.17815 & 6.67035 & 7.8485 \\
CR 7 & 14.3548 & 2.8312 & 5.7618 & 8.593 \\
CR 5 & 12.2623 & 4.9957 & 3.6333 & 8.629 \\
\hline
\end{tabular}

\section{AHP/DEA method}

The DEA method divides the considered units into two efficient and inefficient groups. The units which score 1 in efficiency are defined as efficient and the others, with efficiency less than 1, are named inefficient ones. The main problem is to rank and prioritize the efficient while the inefficient units are ranked spontaneously. The presented hybrid DEA/AHP method is to rank decision making units [41]. In this method, a DEA model is initially implemented for each pair of units regardless of other units. Afterwards, using the outcomes of solving DEA models, a paired comparison matrix is formed. Then, the AHP method is implemented in level 1 to fully rank the units.

The proposed method has some major advantages. The inconsistency resulted from mental judgments in a paired comparison matrix of the AHP is removed. The constraints of enterprises are relaxed towards inputs and outputs. Since in the DEA method, the number of enterprises in comparison with the number of inputs and outputs is relatively high, it leads to a situation that most enterprises score one in efficiency. As a consequence, prioritizing them can be difficult. In this method, each enterprise is compared with others and its efficiency score is calculated. Therefore, the 


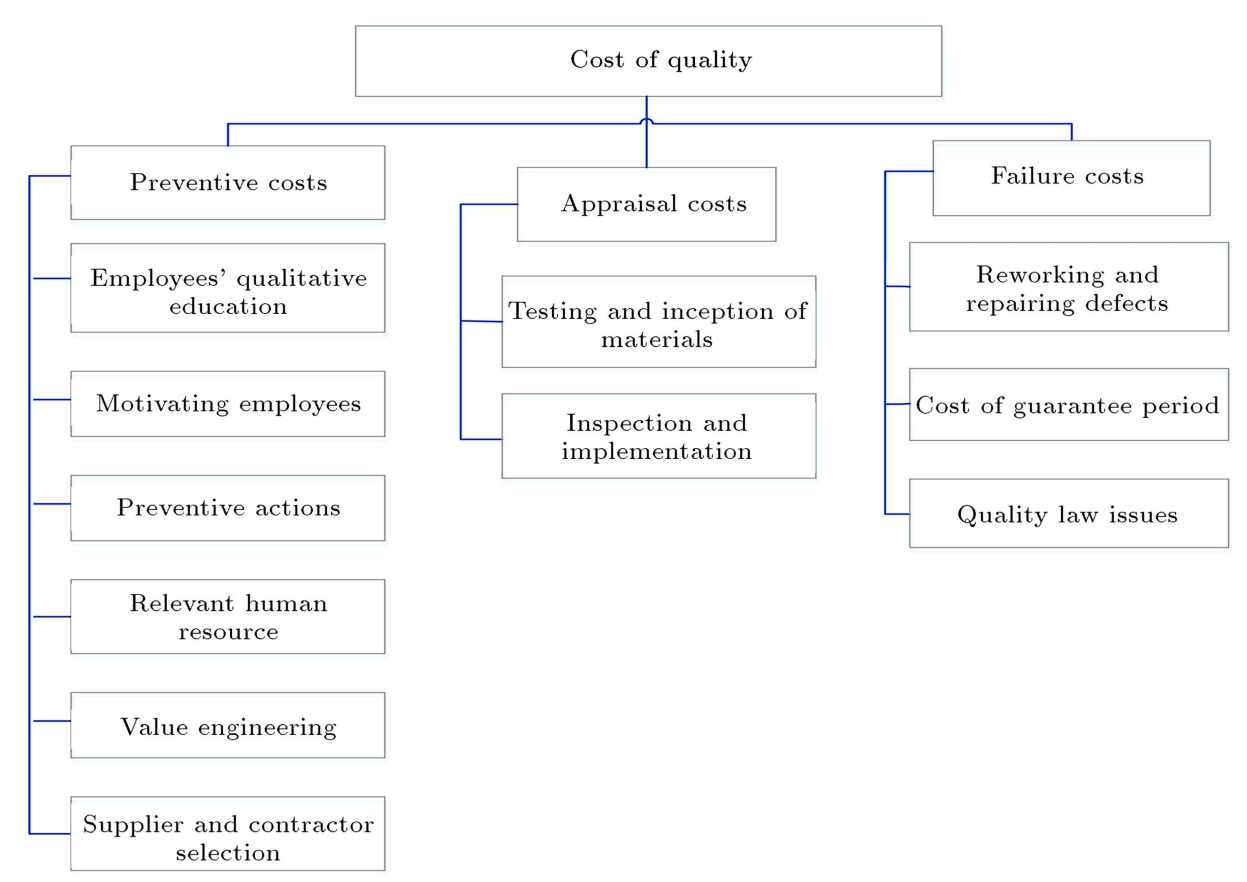

Figure 2. Recognition framework cost of quality in construction projects.

much efficient enterprise obtains higher weight than the others do. In this paper, to evaluate suppliers with the DEA method, wastes, quality costs, and delivery are deemed to be inputs and the others are considered as outputs. Moreover, in order to evaluate contractors, reworking costs are assumed as inputs and the others are considered as outputs.

\section{Supply chain design in construction projects}

In this study, an innovative dynamic supply chain for a real case study in a construction project is presented. The case study is considered in a civil enterprise, namely, P.G. Company. In this hybrid method, suppliers and contractors are first selected through the hybrid AHP/DEA/FDEMATEL method. While implementing the project, the project management office and quality assurance unit are in touch with a contractor and continuously assess the project; also, in case of disruption and failure, the main contractor will be summoned. In the next step, some new indicators are defined and combined with the first introduced ones to evaluate suppliers and contractors when the project is finished by project managers. This process is again based on the hybrid DEA/AHP method and the best ones are selected to establish a rich data base for the upcoming projects. In fact, the continuous evaluation of projects before initialization, during the execution, and after completion is an agile approach (it is noteworthy that agility is matched with EFQM 2013 and PMBOK, Fifth Edition) to supplier and contractor evaluation in construction projects' SCM. This model is shown in Figure 4.

\subsection{Measuring agility in Construction Supply Chain Model (CSCM)}

In this paper, due to importance and novelty of agility in civil projects, we decided to measure the agility in civil projects through Yield Process method:

$$
\begin{aligned}
& \text { Agility }=\text { Yield } \text { Process }_{\text {overal }}=f(\text { Yield Process } \text { circle1 } \\
& + \text { Yield Process } \text { circle2 }_{2}+\text { Yield Process } \text { circle3 } \\
& \left.+ \text { Yield Process }{ }_{\text {circle3 }}\right)
\end{aligned}
$$

where $A$ shows the importance rate of each circle in total Yield Process and $x_{n}$ defines each Yield Process in its circle. Therefore, regarding Eqs. (7) and (8), the main equation is as follows:

$$
Y P_{\text {overal }}=A x_{\text {circle } 1}+B x_{\text {circle } 2}+C x_{\text {circle } 3}+D x_{\text {circle } 3} \text {. }
$$

With respect to Figures 3 and 4, each circle is calculated; for instance, circle3 and circle4 show CSI1 (Customer Satisfaction Index) and CSI2. To boost the agility in the supply chain of civil projects, it is necessary to obtain large values for Yield Process. Hence, the total quality cost, mentioned in Section 3.2, will be optimized.

\subsection{Ranking suppliers/contractors using a hybrid method}

Tables 4 and 5 show the rankings for suppliers and contractors according to the hybrid DEA/AHP method. 


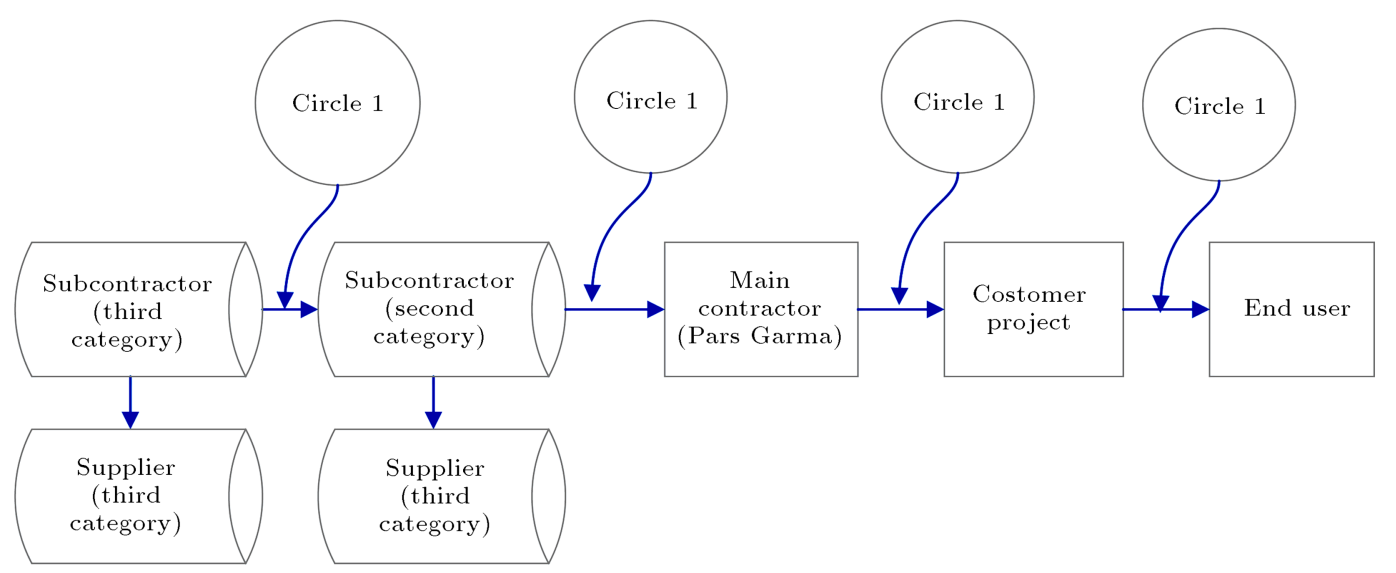

Figure 3. Measuring yield process.

Table 4. Ranking of suppliers by the DEA/AHP method.

\begin{tabular}{|c|c|c|c|c|c|}
\hline Rank & Supplier & Weight & Rank & Supplier & Weight \\
\hline 1 & $\mathrm{DMU}_{5}$ & 0.04619 & 21 & $\mathrm{DMU}_{23}$ & 0.02274 \\
\hline 2 & $\mathrm{DMU}_{6}$ & 0.04532 & 22 & $\mathrm{DMU}_{31}$ & 0.02215 \\
\hline 3 & $\mathrm{DMU}_{19}$ & 0.04499 & 23 & $\mathrm{DMU}_{39}$ & 0.02185 \\
\hline 4 & $\mathrm{DMU}_{21}$ & 0.04442 & 24 & $\mathrm{DMU}_{13}$ & 0.02148 \\
\hline 5 & $\mathrm{DMU}_{24}$ & 0.04342 & 25 & $\mathrm{DMU}_{1}$ & 0.02142 \\
\hline 6 & $\mathrm{DMU}_{29}$ & 0.04294 & 26 & $\mathrm{DMU}_{4}$ & 0.02087 \\
\hline 7 & $\mathrm{DMU}_{33}$ & 0.04206 & 27 & $\mathrm{DMU}_{10}$ & 0.01935 \\
\hline 8 & $\mathrm{DMU}_{2}$ & 0.04114 & 28 & $\mathrm{DMU}_{22}$ & 0.01917 \\
\hline 9 & $\mathrm{DMU}_{15}$ & 0.03910 & 29 & $\mathrm{DMU}_{32}$ & 0.01783 \\
\hline 10 & $\mathrm{DMU}_{26}$ & 0.03557 & 30 & $\mathrm{DMU}_{38}$ & 0.01755 \\
\hline 11 & $\mathrm{DMU}_{37}$ & 0.03436 & 31 & $\mathrm{DMU}_{20}$ & 0.01367 \\
\hline 12 & $\mathrm{DMU}_{27}$ & 0.03198 & 32 & $\mathrm{DMU}_{25}$ & 0.01264 \\
\hline 13 & $\mathrm{DMU}_{30}$ & 0.03178 & 33 & $\mathrm{DMU}_{18}$ & 0.01238 \\
\hline 14 & $\mathrm{DMU}_{36}$ & 0.03052 & 34 & $\mathrm{DMU}_{28}$ & 0.01133 \\
\hline 15 & $\mathrm{DMU}_{3}$ & 0.02963 & 35 & $\mathrm{DMU}_{7}$ & 0.01037 \\
\hline 16 & $\mathrm{DMU}_{9}$ & 0.02943 & 36 & $\mathrm{DMU}_{8}$ & 0.00986 \\
\hline 17 & $\mathrm{DMU}_{11}$ & 0.02537 & 37 & $\mathrm{DMU}_{16}$ & 0.00703 \\
\hline 18 & $\mathrm{DMU}_{12}$ & 0.02474 & 38 & $\mathrm{DMU}_{34}$ & 0.00535 \\
\hline 19 & $\mathrm{DMU}_{14}$ & 0.02351 & 39 & $\mathrm{DMU}_{35}$ & 0.00353 \\
\hline 20 & $\mathrm{DMU}_{17}$ & 0.02297 & & & \\
\hline
\end{tabular}

Due to some confidential issues, instead of unit names, we use the DMU to show suppliers and contractors. It is worth mentioning that supplier and contractor evaluation in the P.G. Company is conducted just for a specific project. The AHP method is done via Excel VBA and the resulted rankings are executed through the DEA method in GAMS 24.1.2 software on a Pentium 4 system with $2.3 \mathrm{GHz}$ and 4GB RAM.

\section{Conclusions and future studies}

In this paper, for the first time in Iran, we have studied and designed a supply chain for civil companies. A hybrid AHP/DEA/FDEA method has been proposed and used to evaluate and prioritize the suppliers and
Table 5. Ranking of contractors by the DEA/AHP method.

\begin{tabular}{cccccc}
\hline Rank & Supplier & Weight & Rank & Supplier & Weight \\
\hline 1 & DMU $_{3}$ & 0.049696 & 27 & DMU $_{1}$ & 0.017424 \\
2 & DMU $_{10}$ & 0.048589 & 28 & DMU $_{2}$ & 0.016682 \\
3 & DMU $_{6}$ & 0.048181 & 29 & DMU $_{5}$ & 0.016565 \\
4 & DMU $_{7}$ & 0.047718 & 30 & DMU $_{15}$ & 0.016546 \\
5 & DMU $_{12}$ & 0.046327 & 31 & DMU $_{16}$ & 0.015493 \\
6 & DMU $_{32}$ & 0.044829 & 32 & DMU $_{17}$ & 0.014389 \\
7 & DMU $_{48}$ & 0.040911 & 33 & DMU $_{23}$ & 0.013843 \\
8 & DMU $_{20}$ & 0.030139 & 34 & DMU $_{30}$ & 0.013533 \\
9 & DMU $_{21}$ & 0.02941 & 35 & DMU $_{31}$ & 0.013153 \\
10 & DMU $_{27}$ & 0.028504 & 36 & DMU $_{37}$ & 0.010151 \\
11 & DMU $_{29}$ & 0.028491 & 37 & DMU $_{41}$ & 0.00994 \\
12 & DMU $_{35}$ & 0.027769 & 38 & DMU $_{43}$ & 0.009439 \\
13 & DMU $_{36}$ & 0.024992 & 39 & DMU $_{47}$ & 0.009257 \\
14 & DMU $_{39}$ & 0.024818 & 40 & DMU $_{14}$ & 0.008389 \\
15 & DMU $_{42}$ & 0.023091 & 41 & DMU $_{22}$ & 0.0083 \\
16 & DMU $_{50}$ & 0.021914 & 42 & DMU $_{26}$ & 0.008151 \\
17 & DMU $_{18}$ & 0.021627 & 43 & DMU $_{28}$ & 0.008096 \\
18 & DMU $_{19}$ & 0.020757 & 44 & DMU $_{8}$ & 0.006945 \\
19 & DMU $_{25}$ & 0.019996 & 45 & DMU $_{33}$ & 0.006167 \\
20 & DMU $_{34}$ & 0.019083 & 46 & DMU $_{9}$ & 0.00531 \\
21 & DMU $_{38}$ & 0.01906 & 47 & DMU $_{11}$ & 0.004466 \\
22 & DMU $_{40}$ & 0.018868 & 48 & DMU $_{24}$ & 0.004372 \\
23 & DMU $_{44}$ & 0.018637 & 49 & DMU $_{13}$ & 0.003265 \\
24 & DMU $_{45}$ & 0.018566 & 50 & DMU $_{4}$ & 0.002139 \\
25 & DMU $_{46}$ & 0.018462 & & & \\
26 & DMU $_{49}$ & 0.017549 & & & \\
\hline & & & & & \\
\hline
\end{tabular}

contractors in the network. First, the most influential indicators have been chosen by a fuzzy DEMATEL method. Afterwards, suppliers and contractors have been evaluated according to the DEA method and the selected indicators. However, regarding inefficiency of most units, we have applied a hybrid DEA/AHP method. Furthermore, in this study, we have focused on agility of a supply chain. In addition to agility, 


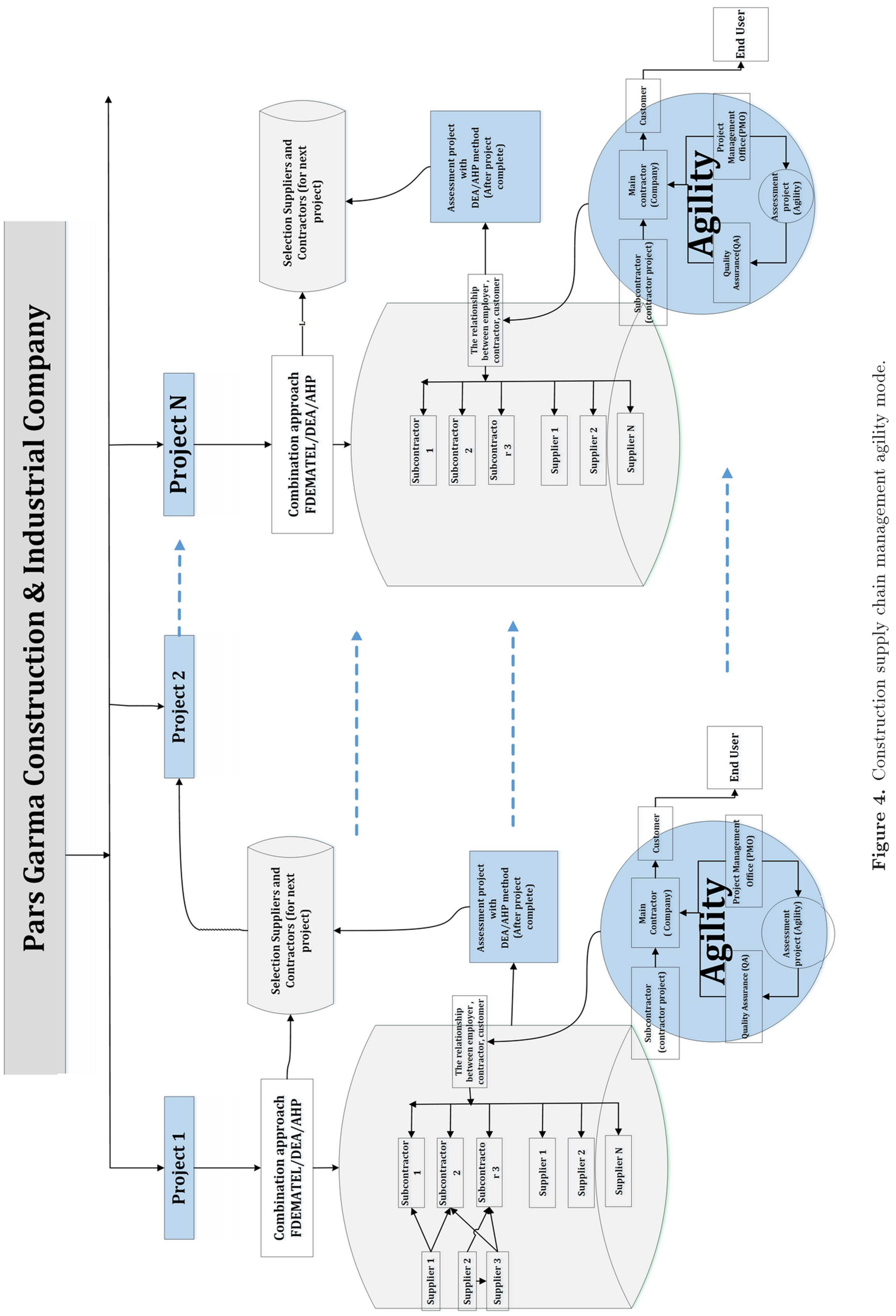


it is dynamic and virtual; thus, it is applicable for different projects. Quality costs have been optimized through applying a yield process approach to agility of the supply chain. For future research, it is worthwhile to contribute portfolio management into the proposed model.

\section{References}

1. Simchi-Levi, D., Kaminsky, P. and Simchi-Levi, E., Designing and Managing the Supply Chain: Concepts, Strategies and Case Studies, 3rd Ed., McGrawHill/Irwin (2007).

2. Thomas, D.J. and Griffin, P.M. "Coordinated supply chain management", European Journal of Operation Research, 94, pp. 1-15 (1996).

3. Stadtler, H. and Kilger, C., Supply Chain Management and Advanced Planning: Concepts, Models, Software and Case Studies, Springer Verlag (2005).

4. Tabrizi, B.H. and Razmi, J. "A stochastic programming based approach for supply chain network design under uncertain processing costs", In: Proceedings of the 11th Asia Pacific Industrial Engineering and Management Systems Conference (2010).

5. Chopra, S. and Meindle, P., Supply Chain Management: Strategy, Planning, and Operations, 2nd Ed., Upper Sadle River: Pearson (2004).

6. Benton, W.C. and McHenry, L.F., Construction Purchasing \& Supply Chain Management, Mc-Graw Hill, New York (2010).

7. Wind, Y. and Robinson, P.J. "The determinants of vendor selection: The evaluation function approach", Journal of Purchasing and Materials Management, 4(3), pp. 29-41 (1965).

8. Stevens, G.C. "Integrating the supply chain", International Journal of Physical Distribution and Materials Management, 19, pp. 3-8 (1989).

9. Sharma, D., Benton, W.C. and Srivastava, R. "Competitive strategy and purchasing decisions", In: Proceedings of the 1989 Annual Conference of the Decision Sciences Institute, pp. 1088-1090 (1989).

10. Morlacchi, P. "Vendor evaluation and selection: the design process and a fuzzy-hierarchical model", In: Proceedings of the 8th IPSERA Conference, Dublin (1999).

11. Simpson, P.M., Siguaw, J.A. and White, S.C. "Measuring the performance of suppliers: An analysis of evaluation processes", Journal of Supply Chain Management, 38, pp. 29-41 (2003).

12. Al-Faraj, T.N., Alidi, A.S. and Al-Zayer, J.A. "Vendor selection via a spreadsheet analytical hierarchy process", Computers and Industrial Engineering, 25(1-4), pp. 65-68 (1993).

13. Bhutta, K.S. and Huq, F. "Supplier selection problem: A comparison of totalcost of ownership and analytical hierarchy process approach", Supply Chain Management: An International Journal, 7, pp. 126-135 (2002).
14. Wang, G., Huang, S.H. and Dismukes, J.P. "Productdriven supply chain selection using integrated multicriteria decision-making methodology", International Journal of Production Economics, 91, pp. 1-15 (2004).

15. Bello, M.J.S. "A case study approach to the supplier selection process", Master Thesis, University of Puerto Rico (2003).

16. Ding, H., Benyoucef, L. and Xie, X. "A simulationoptimization approach using genetic search for supplier selection", In: Proceedings of the 2003 Winter Simulation Conference (2003).

17. Das, S.K. and Shahin, H. "Models for supply chain vendor selection in E-Markets", Journal of the Chinese Institute of Industrial Engineers, 20, pp. 231-239 (2003).

18. Razmi, J., Rafiei, H. and Hashemi, M. "Designing a decision support system to evaluate and select suppliers using fuzzy analytic network process", Computers \& Industrial Engineering, 57, pp. 1282-1290 (2009).

19. Azadeh, A. and Alem, S.M. "A flexible deterministic, stochastic and fuzzy data envelopment analysis approach for supply chain risk and vendor selection problem: Simulation analysis", Expert Systems with Applications, 37, pp. 7438-7448 (2010).

20. Liu, J., Ding, F.Y. and Lall, V. "Using data envelopment analysis to compare suppliers for supplier selection and performance improvement", Supply Chain Management: An International Journal, 5, pp. 143150 (2000).

21. Weber, C.A., Current, J.R. and Desai, A. "Noncooperative negotiation strategies for vendor selection", European Journal of Operational Research, 108, pp. 208-223 (1998).

22. Kahraman, C., Cebeci, U. and Ulukan, Z. "Multicriteria supplier selection using fuzzy AHP", Logistics, Information Management, 16, pp. 382-394 (2003).

23. Guneri, A.F., Yucel, A. and Ayyildiz, G. "An integrated fuzzy-LP approach for a supplier selection problem in supply chain management", Expert Systems with Applications, 36, pp. 9223-9228 (2009).

24. Reza, S. "Supplier selection by the new AR-IDEA model", International Journal of Advanced Manufacturing Technology, 39, pp. 1061-1070 (2009).

25. Sevkli, M., Lenny Koh, S.C., Zaim, S., Demirbag, M. and Tatoglu, E. "An application of data envelopment analytic hierarchy process for supplier selection: A case study of BEKO in Turkey", International Journal of Production Research, 45, pp. 1973-2003 (2007).

26. Kuo, R.J., Lee, L.Y. and Hu, T.L. "Developing a supplier selection system through integrating fuzzy AHP and fuzzy DEA: A case study on an auto lighting system company in Taiwan", Production Planning \& Control: The Management of Operations, 21, pp. 468484 (2010).

27. Zeydan, M., Çolpan, C. and Çobanoğlu, C. "A combined methodology for supplier selection and performance evaluation", Expert Systems with Applications, 38, pp. 2741-2751 (2011). 
28. Zhang, X., Lee, C.K. and Chen, S. "Supplier evaluation and selection: A hybrid model based on DEAHP and ABC", International Journal of Production Research, 50, pp. 1877-1889 (2012).

29. Li, W., Chen, Y. and Fu, Y. "Combination of TOPSIS and 0-1 programming for supplier selection", In: Proceedings of the IEEE International Conference on Supply Chain Management, Networking, Sensing and Control (ICNSC), pp. 1531-1535 (2008).

30. Lin, Y.T, Lin, L., Yu, H.C. and Tzeng, G.H. "A novel hybrid MCDM approach for outsourcing vendor selection: A case study for a semiconductor company in Taiwan", Expert Systems with Applications, 37, pp. 4796-804 (2010).

31. Ou Yang, Y.P., Shieh, H.M., Leu, J.D. and Tzeng, G.H. "A novel hybrid MCDM model combined with DEMATEL and ANP with applications", International Journal of Operations Research, 5, pp. 160-168 (2008).

32. Xu, J. and Yan, F. "A multi-objective decision making model for the vendor selection problem in a bi-fuzzy environment", Expert Systems with Applications, 38, pp. 9684-9695 (2011).

33. Amindoust, A., Ahmed, S.H. and Saghafinia, A. "Location decision of supply chain management in the auto motive industry", International Journal of Engineering and Applied Sciences, 1, pp. 64-67 (2012).

34. Arabzad, S.M., Bahrami, M. and Ghorbaniz, M. "Integrating Kano-DEA models for distribution evaluation problem", Procedia-Social and Behavioral Sciences, 41, pp. 506-512 (2012).

35. Lee, A.H.I. "A fuzzy supplier selection model with the consideration of benefits, opportunities, costs and risks", Expert Systems with Applications, 36(2), pp. 2879-2893 (2009).

36. Carrera, D.A and Mayorga, R.V. "Supply chain management: A modular fuzzy inference system approach in supplier selection for new product development", Journal of Intelligent Manufacturing, 19, pp. 1-12 (2008).

37. Çelebi, D. and Bayraktar, D. "An integrated neural network and data envelopment analysis for supplier evaluation under incomplete information", Expert Systems with Applications, 35, pp. 1698-1710 (2008).

38. Wu, D. "Supplier selection: A hybrid model using DEA, decision tree and neural network", Expert Systems with Applications, 36, pp. 9105-9112 (2009).

39. Sanayei, A., Mousavi, S.F. and Yazdankhah, A. "Group decision making process for supplier selection with VIKOR under fuzzy environment", Expert Systems with Applications, 37, pp. 24-30 (2010).

40. Shi, C.D., Bian, D.X. and Li, S.L. "Application of BP neural network and DEA in the logistics supplier selection", In: Proceedings of the 2nd International Conference on Computer Engineering and Technology (ICCET), pp. 361-364 (2010).
41. Sinuany-Stern, Z., Mehrez, A. and Hadad, H. "An AHP/DEA methodology for ranking decision making units", International Transactions in Operational Research, 7, pp. 109-124 (2000).

42. Cai, Y. and Wu, W. "Synthetic financial evaluation by a method of combining DEA with AHP", International Transactions in Operational Research, 8, pp. 603-609 (2001).

43. Fontela, E. and Gabus, A. "The DEMATEL observer", DEMATEL 1976 Report Switzerland Geneva: Battelle Geneva Research Centre (1976).

44. Azadeh, A., Rezaei-Malek, M., Evazabadian, F. and Sheikhalishahi, M. "Improved design of CMS by considering operators decision-making styles", International Journal of Production Research, 53, pp. 32763287 (2015).

45. Zahiri, B., Tavakkoli-Moghaddam, R. and RezaeiMalek, M. "An MCDA-DEA approach for mixedmodel assembly line balancing problem under uncertainty", Journal of Intelligent \& Fuzzy Systems, 30, pp. 2737-2748 (2016).

46. Chang, B., Chang, C.W. and Wu, C.H. "Fuzzy DEMATEL method for developing supplier selection criteria", Expert Systems with Applications, 38, pp. 1850-1858 (2011).

47. Wu, W.W. and Lee, Y.T. "Developing global manager's competencies using the fuzzy DEMATEL method", Expert Systems with Applications, 32, pp. 499-507 (2007).

48. Kazaz, A., Birgonul, M. and Ulubeyli, S. "Cost-based analysis of quality in developing countries: a case study of building projects", Building and Environment, 40, pp. 1365-1356 (2005).

49. Abdelsalam, H. and Gad, M. "Cost of quality in Dubai: An analytical case study of residential construction projects", International Journal of Project Management, 27, pp. 501-511 (2009).

50. Hall, M. and Tomkins, C. "A cost of quality analysis of a building project: towards a complete methodology for design and build", Construction Management and Economics, 19, pp. 727-740 (2001).

51. Forouzanfar, F., Tavakkoli-Moghaddam, R., Bashiri, M. and Baboli, A. "A new bi-objective model for a closed-loop supply chain problem with inventory and transportation times", Scientia Iranica, Transaction E, 23, pp. 1441-1458 (2016).

\section{Appendix A}

Figures A.1 and A.2. show the representation of the vertical and horizontal supply chains in construction projects, respectively.

\section{Appendix B}

Tables B.1 and B.2 show the supplier and contractor's criteria scores, respectively. 


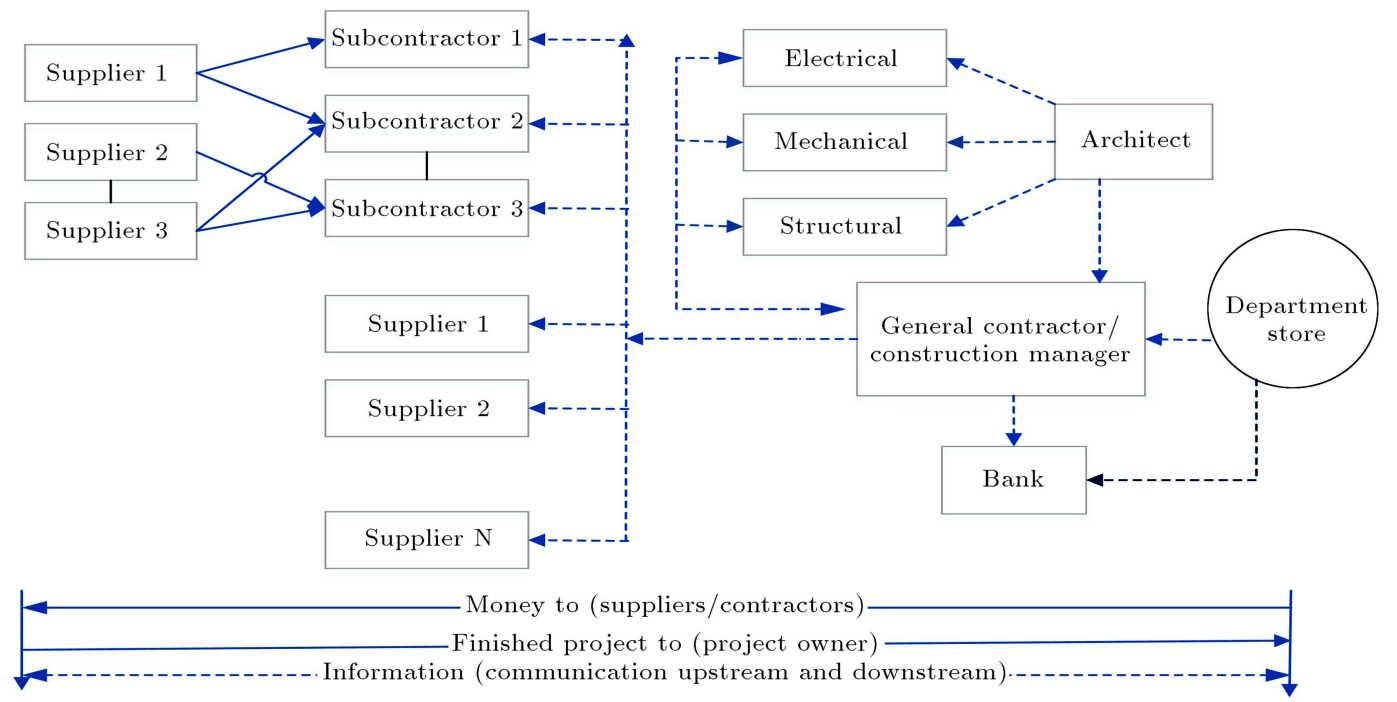

Figure A.1. Representation of supply chain in vertical construction projects in private and public sections.

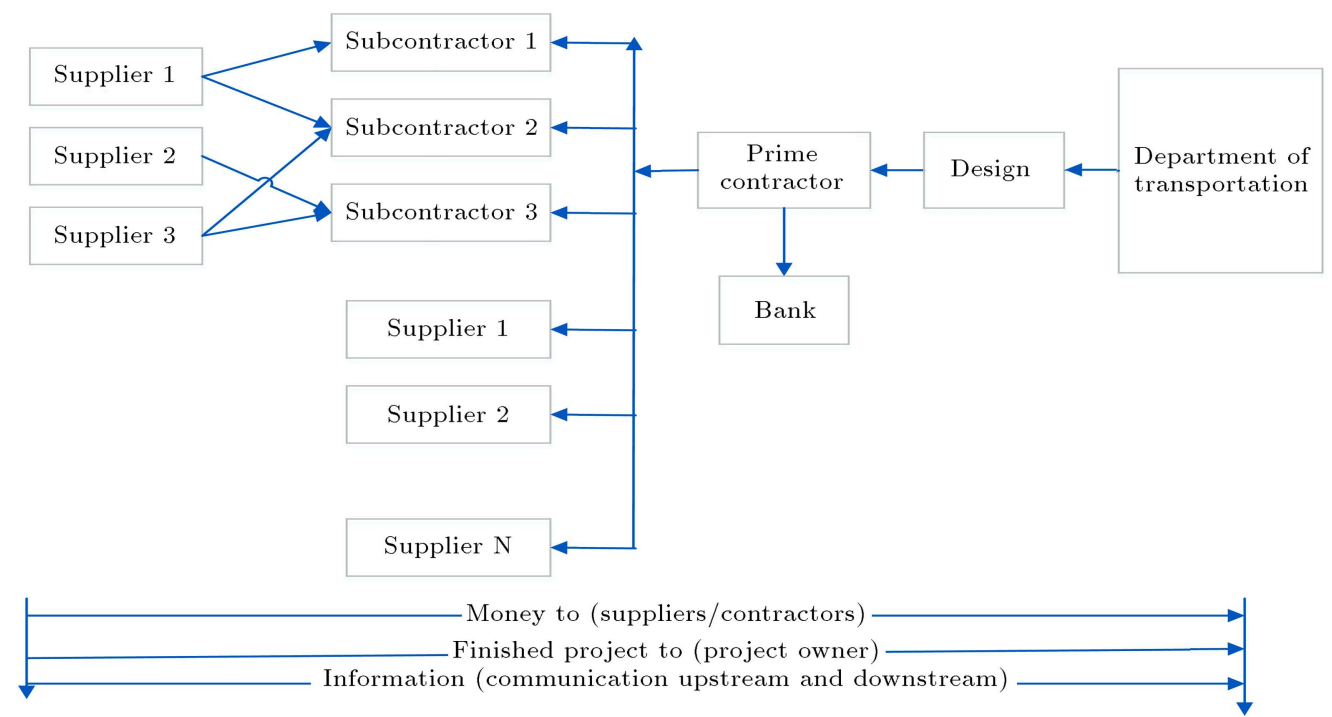

Figure A.2. Representation of horizontal supply chain and large-scale construction projects in public sections.

Table B.1. Criteria scores of suppliers.

\begin{tabular}{|c|c|c|c|c|c|}
\hline $\begin{array}{l}\text { Cost of } \\
\text { quality }\end{array}$ & $\begin{array}{c}\text { Guarantee and } \\
\text { warranty }\end{array}$ & $\begin{array}{c}\text { Waste and } \\
\text { damages }\end{array}$ & Equipment & Delivery & Supplier \\
\hline 0.0282 & 0.0296 & 0.0308 & 0.0221 & 0.0276 & 1 \\
\hline 0.0282 & 0.0296 & 0.0308 & 0.0294 & 0.0276 & 2 \\
\hline 0.0282 & 0.0222 & 0.0308 & 0.0294 & 0.0276 & 3 \\
\hline 0.0282 & 0.0222 & 0.0308 & 0.0221 & 0.0276 & 4 \\
\hline- & - & - & - & - & - \\
\hline - & - & - & - & - & - \\
\hline- & - & - & - & - & - \\
\hline 0.0282 & 0.0222 & 0.0154 & 0.0294 & 0.0276 & 37 \\
\hline 0.0282 & 0.0222 & 0.0308 & 0.0221 & 0.0276 & 38 \\
\hline 0.0282 & 0.0296 & 0.0154 & 0.0221 & 0.0276 & 39 \\
\hline
\end{tabular}


Table B.2. Criteria scores of contractors.

\begin{tabular}{|c|c|c|c|c|c|c|c|}
\hline $\begin{array}{c}\text { Ability } \\
\text { technical } \\
\text { and planning }\end{array}$ & Native & Rework costs & Financial & Reliability & History & Experience & Contractors \\
\hline 0.0182 & 0.0127 & 0.0217 & 0.0234 & 0.0196 & 0.0245 & 0.0185 & 1 \\
\hline 0.0182 & 0.0253 & 0.0217 & 0.0156 & 0.0196 & 0.0184 & 0.0185 & 2 \\
\hline 0.0242 & 0.0253 & 0.0109 & 0.0234 & 0.0261 & 0.0245 & 0.0247 & 3 \\
\hline 0.0121 & 0.0127 & 0.0217 & 0.0156 & 0.0196 & 0.0184 & 0.0185 & 4 \\
\hline - & - & - & - & - & - & - & - \\
\hline - & - & - & - & - & - & - & - \\
\hline - & - & - & - & - & - & - & - \\
\hline 0.0242 & 0.0190 & 0.0109 & 0.0234 & 0.0196 & 0.0184 & 0.0185 & 48 \\
\hline 0.0242 & 0.0253 & 0.0217 & 0.0156 & 0.0196 & 0.0184 & 0.0185 & 49 \\
\hline 0.0182 & 0.0253 & 0.0109 & 0.0156 & 0.0196 & 0.0184 & 0.0247 & 50 \\
\hline
\end{tabular}

\section{Biographies}

Yaser Rahimi is a PhD student of Industrial Engineering in the Collage of Engineering at University of Tehran, Iran. He received his MSc degree in Industrial Engineering from University of Tehran, Iran, in 2014 and his BSc degree in Industrial Engineering from University of Kurdistan, Iran, in 2011. His research interests include hub location, transportation, operations research, meta-heuristic methods, exact optimization methods, and supply chain management. Yaser Rahimi published 12 papers related to hub location problems and supply chain in journals.

Reza Tavakkoli-Moghaddam is Professor of Industrial Engineering in the College of Engineering at University of Tehran, Iran. He obtained his BSc, MSc, and $\mathrm{PhD}$ degrees from Iran University of Science and Technology, Tehran, in 1989; University of Melbourne, Melbourne, in 1994; and Swinburne University of Technology, Melbourne, in 1998, respectively. He serves as the Editor-in-Chief of two journals and the Editorial Board Member of five journals. He was the recipient of the 2009 and 2011 Distinguished Researcher Awards as well as the 2010 and 2014 Distinguished Applied Research Awards by University of Tehran in Iran. He was also selected as National Iranian Distinguished Researcher in 2008 and 2010 by the Ministry of Science, Research and Technology (MSRT) in Iran. He obtained the outstanding rank of being among the top $1 \%$ scientists and researchers in the world elite group, reported by Thomson Reuters in 2014. Professor Tavakkoli-Moghaddam has published 4 books, 17 book chapters, and more than 700 papers in reputable academic journals and conferences.

Sirous Shojaie received his MSc degree in Industrial Engineering at Iran University of Science and Technology in Iran (2014). He obtained his BSc degree in Industrial Engineering from the Imam Hossein Comprehensive University in Tehran, Iran, in 2001. His research interests include location, transportation, quality management system, six-sigma, and total quality management.

Esmail Cheraghi received his MSc degree in Industrial Engineering from Collage of Engineering at University of Tehran, Iran, in 2015. He obtained his BSc degree in Theory Economics from Allameh Tabataba' $i$ University, Iran, in 1985. His research interests include location, transportation, quality management system, hub location, and finance management. 